\title{
Chronic Reduction of Endocochlear Potential Reduces Auditory Nerve Activity: Further Confirmation of an Animal Model of Metabolic Presbyacusis
}

\author{
Hainan Lang ${ }^{1}$, Vinu Jyothi ${ }^{1}$, Nancy M. Smythe ${ }^{2}$, Judy R. Dubno ${ }^{1,2}$, Bradley A. Schulte ${ }^{1,2}$, \\ AND Richard A. SCHMIEDT ${ }^{2}$ \\ ${ }^{1}$ Department of Pathology and Laboratory Medicine, Medical University of South Carolina, 165 Ashley Avenue, MSC 908, \\ Charleston, SC 29425, USA \\ ${ }^{2}$ Department of Otolaryngology-Head E Neck Surgery, Medical University of South Carolina, Charleston, SC 29425, USA
}

Received: 14 August 2009; Accepted: 8 March 2010; Online publication: 6 April 2010

\begin{abstract}
Gerbils aged in quiet show a decline of the endocochlear potential (EP) and elevated auditory nerve compound action potential (CAP) thresholds. However, establishing a direct relationship between an age-related reduction in the EP and changes in the activities of primary auditory neurons is difficult owing to the complexity of age-related histological changes in the cochlea. To address this issue, we developed a young gerbil model of "metabolic" presbyacusis that uses an osmotic pump to deliver furosemide into the round window niche for 7 days, resulting in a chronically reduced EP. In this model, the only major histopathologic changes were restricted to the hook region of the cochlea and consisted of loss of strial intermediate cells and massive edema in the lateral wall. The morphological and physiological evidence suggests that the cochlea can adapt to furosemide application over time. The morphology of spiral ganglion cells and hair cells appeared normal throughout the cochlea. CAP responses and EP values in this model are similar to those of quiet-aged ears. The spontaneous activity of single auditory fibers $(n=$ 188) was assessed in 15 young gerbils treated with furosemide for 7 days. The percentage of recorded low-spontaneous rate (SR) fibers at characteristic frequencies $(\mathrm{CFs}) \geq 6 \mathrm{kHz}$ was significantly lower in furosemide-treated than in control ears. Recovery
\end{abstract}

Correspondence to: Hainan Lang - Department of Pathology and Laboratory Medicine - Medical University of South Carolina 165 Ashley Avenue, MSC 908, Charleston, SC 29425, USA. Telephone: +843-792-2711; fax: +843-792-0368; email: langh@musc.edu function tests of CAP responses after prior stimulation also showed a decline in activity of the low-SR population with $\mathrm{CFs} \geq 6 \mathrm{kHz}$ in the treated cochleas. A similar loss in the activity of low-SR fiber has been previously shown in quiet-aged gerbils. These results suggest that dysfunction of the cochlear lateral wall and subsequent chronic reduction in the EP can directly affect the activity patterns of primary auditory neurons in a manner similar to that seen in aged gerbils.

Keywords: age-related hearing loss, endocochlear potential, auditory nerve, spontaneous activity, furosemide, cochlear lateral wall, stria vascularis

\section{INTRODUCTION}

Age-related hearing loss (presbyacusis) is the most common type of hearing impairment in humans. Schuknecht (1974) has described four types of human presbyacusis: (1) sensory, mainly affecting sensory hair cells and supporting cells; (2) neural, typified by the loss of spiral ganglion neurons; (3) metabolic, with deficits in the active processes by which ionic gradients are maintained, caused mainly by degeneration of cells in the stria vascularis and fibrocytes in spiral ligament; and (4) mechanical, presumably from a stiffened basilar membrane and organ of Corti. In a later report, Schuknecht and Gacek (1993) described atrophy of the cochlear lateral wall as the predominant lesion in the temporal bones of old humans. 
They also concluded that sensory cell loss was the least important cause of hearing loss in old adults, unless associated with confounding factors such as noise and drug exposure or genetic defects. Previous studies in our and other laboratories using gerbil and mouse models have shown that cochlear lateral wall pathology, including the degeneration of strial cells and fibrocytes in the spiral ligament, is a major pathology in aged ears (Schulte and Schmiedt 1992; Spicer et al. 1997; Hequembourg and Liberman 2001; Spicer and Schulte 2002; 2005; Wu and Marcus 2003; Ohlemiller 2004). The loss or diminished function of the cells in the cochlear lateral wall can lead to disruption of inner ear ion and fluid homeostasis, with a subsequent EP decline. Indeed, gerbils aged in quiet show an age-related decline in EP and disruption of ion homeostasis in the cochlea (Schulte and Schmiedt 1992; Schmiedt 1996). In addition, the reduction of the EP in aged ears has been associated with the elevation in CAP thresholds, especially at high frequencies (Hellstrom and Schmiedt 1990; Schmiedt et al. 2002). A causal link between the age-related EP reduction and the decline of activity in the primary auditory afferent nerve fibers remains to be established.

Auditory nerve fibers discharge spontaneously without sound stimuli. Spontaneous rate classes of auditory afferent fibers were determined first by Kiang et al. (1965) and further detailed by Liberman (1978) in cats. Auditory afferent fibers with spontaneous rates higher than 18 spikes per second have low thresholds to stimuli, whereas fibers with lower rates have higher thresholds. Similar SR-based functional subdivisions of auditory nerve fibers have now been reported in other mammalian species including chinchilla (Salvi et al. 1982; Relkin and Pelli 1987; Frisina et al. 1996), guinea pig (Winter et al. 1990), gerbil (Schmiedt 1989; Schmiedt et al. 1996; Ohlemiller and Echteler 1990; Ohlemiller et al. 1991; Ohlemiller and Siegel 1994), and mouse (Taberner and Liberman 2005). Older gerbils show a loss of activity in low-SR auditory nerve fibers at high CFs (Schmiedt et al. 1996). These data have led us to hypothesize that declines in the activity of high-CF, low-SR fibers are a consequence of the lowered EP in these old gerbils. However, the complexity of histopathological changes in the aging cochlea makes it difficult to assess directly the relationship between age-related EP reductions and decreases in auditory nerve activity. To address this issue, we developed a model of metabolic presbyacusis in young gerbils by using an osmotic pump to deliver furosemide chronically to the cochlea through the intact round window. This results in a young animal model of lateral wall degeneration with a chronic reduction in the EP but without the pathological alterations in the hair cells and neurons that occur with age.
Furosemide is a loop diuretic commonly used in the treatment of congestive heart failure and edema by reducing $\mathrm{Na}-\mathrm{K}-\mathrm{Cl}$ co-transporter (NKCC) activity in the kidney. The NKCC protein is expressed in the stria vascularis, interdental cells, and subpopulations of fibrocytes in the inferior portion of the spiral ligament in young-adult gerbils (Crouch et al. 1997). Previous animal studies have shown that furosemide creates edema in the cochlear lateral wall, reversibly inhibits the EP, and induces hearing loss (Rybak 1993; Sewell 1984; Schmiedt et al. 2000). By controlling the dosage and duration of furosemide application, a chronic reduction in EP can be maintained in an otherwise healthy inner ear with few if any observable morphologic abnormalities in sensory hair cells and spiral ganglion neurons. This furosemide-induced reduction in EP is comparable in magnitude to that seen in quiet-aged gerbils. Here, we employed this animal model to assess the effect of chronic EP reduction on the activity patterns of primary auditory neurons using CAP input/output (I/O) functions, single-unit recordings of spontaneous rates, tuning curves, and CAP recovery functions following conditioning tones. The results provide the first direct evidence that chronic lowering of the EP is the cause of declines in the activity of primary auditory neurons including the basal low-SR fiber system in quiet-aged gerbils.

\section{MATERIALS AND METHODS}

\section{Animal preparation}

Mongolian gerbils were born and raised in a low-noise environment where the median sound level was typically less than $40 \mathrm{~dB}$ sound pressure level (SPL). The animal facilities have full accreditation from the Association for Assessment and Accreditation of Laboratory Animal Care, and all experimental procedures were approved by the local Institutional Animal Care and Use Committee and met the National Institutes of Health guidelines for animal care.

Forty-seven 3 to 6 -month-old young-adult gerbils of either gender were used in this study. The animals were implanted with Alzet $^{\circledR}$ mini-osmotic pumps (model 2004, Durect, Cupertino, CA) with cannulas leading to the round window of the right ear. These pumps are able to deliver solutions continuously for 4 weeks. Untreated left ears were used as contralateral controls for the recording of CAP thresholds, CAP recovery functions, and EPs in most cases. Eleven young-adult animals without treatment were used as controls for single-fiber recordings in the auditory nerve. Data from the young-adult gerbils implanted with furosemide pumps were compared with those obtained from two groups of quiet-aged gerbils: a 
group of 27 gerbils aged 36 months and a group of ten gerbils aged 38 to 45 months. The data from these quiet-aged gerbils were collected over a period of 7 years (Schmiedt et al. 1996, 2002).

Pump implantation was similar to the procedures published previously (Schmiedt et al. 2002; Lang et al. 2003). Animals were anesthetized with sodium pentobarbital $(50 \mathrm{mg} / \mathrm{kg})$ and were given atropine $(0.2 \mathrm{mg} / \mathrm{kg})$ to reduce respiratory secretions. The pumps have a fill volume of about $200 \mu \mathrm{l}$ and a mean pumping rate of $0.25 \mu \mathrm{l} / \mathrm{h}$ at $37^{\circ} \mathrm{C}$. Cannulas were made up of surgical-grade silicon tubing. Pumps were filled with $5 \mathrm{mg} / \mathrm{ml}$ furosemide under sterile conditions and allowed to equilibrate at $37^{\circ} \mathrm{C}$ for $36-48 \mathrm{~h}$ before implantation. The pump was placed subdermally behind the scapula and the cannula routed to the bulla. The cannula was threaded through holes in the bulla and into the round window niche. The surface of the bulla was then sealed with dental cement. Pumps were left implanted for 2 to 3 days, 7 days, or 2 to 4 weeks. At each terminal time point of the experiments, the position of the cannula within the round window niche was carefully checked. The animals were excluded from the experiments if the cannulae became disconnected from the implanted pump. None of the animals showed any signs of infection. The stability of furosemide was checked in situ by high performance liquid chromatography (HPLC) analysis in the pumps implanted for 4 weeks from two animals. No degradation of the furosemide compound was indicated by HPLC measurement in the samples taken from the implanted pumps.

\section{Physiological procedures}

The procedures for recording the CAP thresholds, CAP I/O functions, CAP recovery functions from prior stimulation, distortion production otoacoustic emissions (DPOAEs) and the EP were identical to those previously published for gerbil and mouse (Schmiedt 1996; Lang et al. 2002, 2008). DPOAEs allow testing of outer hair cell function in control and furosemide-treated gerbils. The gerbils were anesthetized with sodium pentobarbital $(50 \mathrm{mg} / \mathrm{kg})$ and fitted to a head holder in a sound- and vibrationisolated booth. The booth was heated to maintain the cochlea at near body temperature $\left(36-37^{\circ} \mathrm{C}\right)$. The pinna and surrounding tissues were removed, and the bulla opened widely. The CAP electrode was placed on the bony rim of the round window niche and referenced to the neck musculature. The acoustic assembly comprising a probe-tube microphone (B\&K 4134, Bruel and Kjaer, Denmark) and driver (Beyer DT-48, Beyerdynamic, Farmingdale, NY) was sealed to the bony ear canal with closed-cell foam. CAP responses were amplified by 10,000 in voltage and filtered between 0.3 and $3.0 \mathrm{kHz}$ at $6 \mathrm{~dB}$ /octave. The tone pips were generated in the frequency domain by Tucker Davis Technologies equipment and software, and the spectrum was normalized across frequency to the average ear canal SPL found in 30 gerbils (Schmiedt et al. 1996). CAP thresholds were obtained visually at half-octave frequencies from 0.5 to $30 \mathrm{kHz}$ with tone pips of $1.8 \mathrm{~ms}$ total duration with $\cos ^{2}$ rise/ fall times of $0.55 \mathrm{~ms}$.

CAP recovery functions were obtained from five animals implanted with furosemide pumps for 7 days. Conditioner and probe tones were presented at 70 and $60 \mathrm{~dB}$ SPL, respectively, at the same frequency. The conditioning tone had 2-ms rise/fall times, the probe, and $0.55-\mathrm{ms}$ rise/fall time. Both stimuli used a $\cos ^{2}$ envelope. The interval $(\Delta \mathrm{T})$ between the conditioner and probe varied from 10 to $600 \mathrm{~ms}$ in two runs. In the first run, $\Delta \mathrm{T}$ varied in the order of 10 , $600,15,500,20,400,30,300,40,200,60,130,80$, and $100 \mathrm{~ms}$. For balance, $\Delta \mathrm{T}$ in the second run was presented in the opposite order. A control response (probe-alone) was obtained at the beginning and end of each run. An average was obtained from a total of 20 presentations of the stimulus at each conditionerprobe interval. Presentations were $1 \mathrm{~s}$ apart. The normalized decremental response was calculated following the example of Relkin et al. (1995):

\section{Normalized decrement}

$$
=(\text { local control }-\mathrm{CAP} \text { amplitude) } / \text { local control. }
$$

"Local control" was the probe-alone response that fell nearest in time to the respective conditioned response.

Single fibers were recorded in the auditory nerve using the ventrolateral approach through the bulla as described previously (Schmiedt 1989; Schmiedt et al. 1990). Fiber recordings were made with glass micropipettes filled with $3 \mathrm{M} \mathrm{NaCl}$. In all animals, only acoustic stimuli were used to search for single fibers. The search stimuli were bursts of wideband noise presented at a maximum of $90 \mathrm{dBA}$. Spontaneous rates were calculated over a 10-s interval, and CF was determined manually. Thresholds of the CAP response to tone pips were monitored throughout the experiment. When the CAP thresholds shifted by more than $10 \mathrm{~dB}$, the experiment was terminated. Such threshold increases most often followed an electrode advancement that compressed a blood vessel within the auditory nerve.

Three classes of afferent fibers in the auditory nerve of the cat have been demonstrated previously by Liberman (1978): a low-SR group with rates below 0.5 spikes per second, a medium-SR group with rates between 0.5 and 18 spikes per second, a high-SR group with rates more than 18 spikes per second. 
However, in the gerbil, the low-SR fibers do not seem to be as obviously separated as seen in the cat (Schmiedt 1989; Suryadevara et al. 2001). Here, the auditory nerve fibers of the gerbil were divided into two classes as used in our previous gerbil study (Schmiedt et al. 1996). Fibers of gerbil auditory nerve were classified as "low-SR" (as low-medium-SR for cat categories) if their spontaneous rates were $\leq 18$ spikes per second and "high-SR" for higher rates. Data from single-unit recording experiments were obtained from 11 young control ears (223 fibers) and 15 furosemidepump implanted ears (188 fibers).

DPOAEs were measured with an ARIEL (Ariel, Cranbury, NJ) board and CUBeDISP (Etymotic Research, Elk Grove Village, IL) software using the B\&K 4134 microphone, probe-tube, and frequency equalizer. The intensity levels of both primaries were fixed at $50 \mathrm{~dB}$ SPL. Primary tones were swept from $f 2=$ 0.5 to $20.0 \mathrm{kHz}$ with an $f 2 / f 1$ ratio of 1.2 and a resolution of 10 points per octave. For clarity in the figures presented here, every other point was dropped for a resolution of 5 points per octave.

EPs were recorded from the basal turn (T1), middle turn (T2), and apical turn (T3) corresponding to approximate frequencies of $16-20 \mathrm{kHz}$, $2.2 \mathrm{kHz}$, and $1 \mathrm{kHz}$, according to the gerbil cochlear frequency map of Müller (1996). The EP was always measured at the end of the experiment with a micropipette filled with $0.2 \mathrm{M} \mathrm{KCl}$ yielding an impedance of approximately $30 \mathrm{M} \Omega$. The output of the micropipette was led to an electrometer (World Precision Instruments FD223) for a direct reading of the potential. EP was defined as the voltage difference between the scala media and a pool of isotonic saline on the neck muscle. The micropipette was introduced into the scala media via $20-30-\mu \mathrm{m}$ holes drilled through the otic capsule in T3, T2, and T1, respectively, at the end of the experiment. After the EP was measured in each turn, the tip of the electrode was placed in a pool of saline in the neck muscles to directly calibrate zero potential. We first measured the $\mathrm{EP}$ in T1, followed by T2 and T3. This procedure minimizes the trauma of inserting the micropipette into one turn and causing a reduction of the EP in other turns (Lang et al. 2002, 2008).

\section{Morphological procedures}

Twelve furosemide-exposed and seven young control gerbils were used. The furosemide-exposed gerbils were implanted with pumps for 2 days $(n=2), 7$ days $(n=3)$, and 2-4 weeks $(n=7)$, respectively. The anesthetized animals were perfused via cardiac catheter first with $10 \mathrm{ml}$ normal saline containing $0.1 \%$ sodium nitrite and then $15 \mathrm{ml}$ of a mixture of $4 \%$ paraformaldehyde and $2 \%$ glutaraldehyde in $0.1 \mathrm{M}$ phosphate buffer, $\mathrm{pH}$ 7.4. After removing the stapes and opening the oval and round windows, $0.5 \mathrm{ml}$ of fixative was perfused gently into the scala vestibuli through the oval window. The inner ears were dissected free and immersed in a fixative overnight at $4^{\circ} \mathrm{C}$. Decalcification was completed by immersion in $100 \mathrm{ml}$ of $120 \mathrm{mM}$ solution of ethylenediamine tetracetic acid (EDTA), $\mathrm{pH} 7.2$, with gentle stirring at room temperature for 2-3 days with daily changes of the EDTA solution. The tissues were postfixed with $1 \%$ osmium tetroxide- $-1.5 \%$ ferrocyanide for $2 \mathrm{~h}$ in the dark, dehydrated and embedded in Epon LX 112 resin. Ultra-thin section were stained with uranyl acetate and lead citrate and examined by electron microscopy. Semi-thin sections approximately $1 \mu \mathrm{m}$ thick were cut and stained with toluidine blue. Micrographs were taken using $100 \times$ magnification under a Zeiss axioscope with a digital Spot camera. The images were opened in Adobe Photoshop CS2 in individual files, then copied and pasted into a new canvas large enough to move them into the location needed to reconstruct the cochlea. Then, at high screen magnification, each individual layer was adjusted to a more precise location and locked together using the Photomerge feature of Adobe Photoshop CS2 software.

\section{Immunocytochemistry}

The inner ears were fixed for 6-8 $\mathrm{h}$ with $4 \%$ paraformaldehyde and then decalcified with EDTA. Tissues were embedded in PARAPLAST ${ }^{\circledR}$ for paraffin sectioning. Deparaffinized and rehydrated sections were immersed in blocking solution for $20 \mathrm{~min}$ and then incubated overnight at $4^{\circ} \mathrm{C}$ with a primary antibody diluted in PBS ( $\mathrm{pH}$ 7.4). The primary antibodies used in this study were rabbit anti-NKCC (1:200, A11122; Crouch et al. 1997). The secondary antibody was biotinylated anti-rabbit IgG (1:150, Vector Laboratories, Burlingame, CA). The binding was detected with avidin-biotin-horeseradish peroxidase (HRP) technique using the Vectastain ABC kit (Vector Laboratories, Burlingame, CA). HRP was visualized with 3,3'-diaminobenzidine tetrahydrochloride.

\section{Statistical analysis}

The data were statistically analyzed using SPSS software. EP values, CAP thresholds, CAP I/O function amplitudes, and the decrement in CAP recovery functions are expressed as mean \pm standard error of the mean. A probability $<0.05$ is considered a statistically significant difference. Differences between the control and furosemide-treated animals and changes over time were analyzed by a mixed repeated analysis of variance (ANOVA), followed by Bonferroni post 
hoc comparisons between groups. Differences in the distribution of SR rate as a function of fiber $\mathrm{CF}$ for young and chronic-furosemide-treated ears were analyzed by the chi-square test. In the CAP recovery function experiments, significant changes in CAP decrements between the control and furosemidetreated animals were established using Student's $t$ test for paired data.

\section{RESULTS}

Histopathological and functional changes in gerbil ears treated chronically with furosemide

Histopathologic changes were examined in 12 ears treated with furosemide from 2 days to 4 weeks and in seven control ears. Between 20 and 40 digital images were captured at $100 \times$ magnification from the lateral wall, Rosenthal's canal, the osseous spiral lamina, and the organ of Corti in all three cochlear turns in each ear examined. The merged images were reconstructed from the multi-image sets using Photomerge (Figs. 1, 2, 5, and 6). This high-resolution imaging procedure allowed us to precisely characterize the pathological changes in furosemide-treated ears.

Figure 1 illustrates pathological changes of the cochlear lateral wall in the extreme basal turn (hook region) of a young-adult gerbil ear exposed to furosemide for 2 days. The results from this animal are representative of the three 2-3 day implanted ears we examined. Massive edema was present in the stria vascularis. Although most of the marginal and basal cells appeared to survive, the morphology of the marginal cells was dramatically altered with a loss of most of their basal processes. The majority of the intermediate cells lost their basic morphologic characteristics. Apoptotic-like structures were present in many intermediate cells. Edematous changes in the spiral ligament were generally minor compared with those in the stria vascularis. Mild edema was present at the boundary between the type I and type III fibrocytes. Notably, small empty-appearing spaces were seen in the cytosol of type III fibrocytes. Similar vacuolization was not observed in type I, II, IV, and V fibrocytes, and cellular organelles appeared normal in these cells. The morphology of the cochlear lateral wall in the apical, middle, and upper basal turns was normal (Fig. 2A, B). No pathological abnormalities were seen in the spiral ganglion neurons (Fig. 2C) or sensory hair cells in any region of the cochlea including the hook, although small vacuole-like spaces were occasionally seen beneath IHCs (Fig. 2D).

Auditory function measurements including CAP, $\mathrm{EP}$, and DPOAE in the furosemide-treated and control ear of the gerbil described above are shown in Figure 3. In the treated ear, the EP declined to $37 \mathrm{mV}$

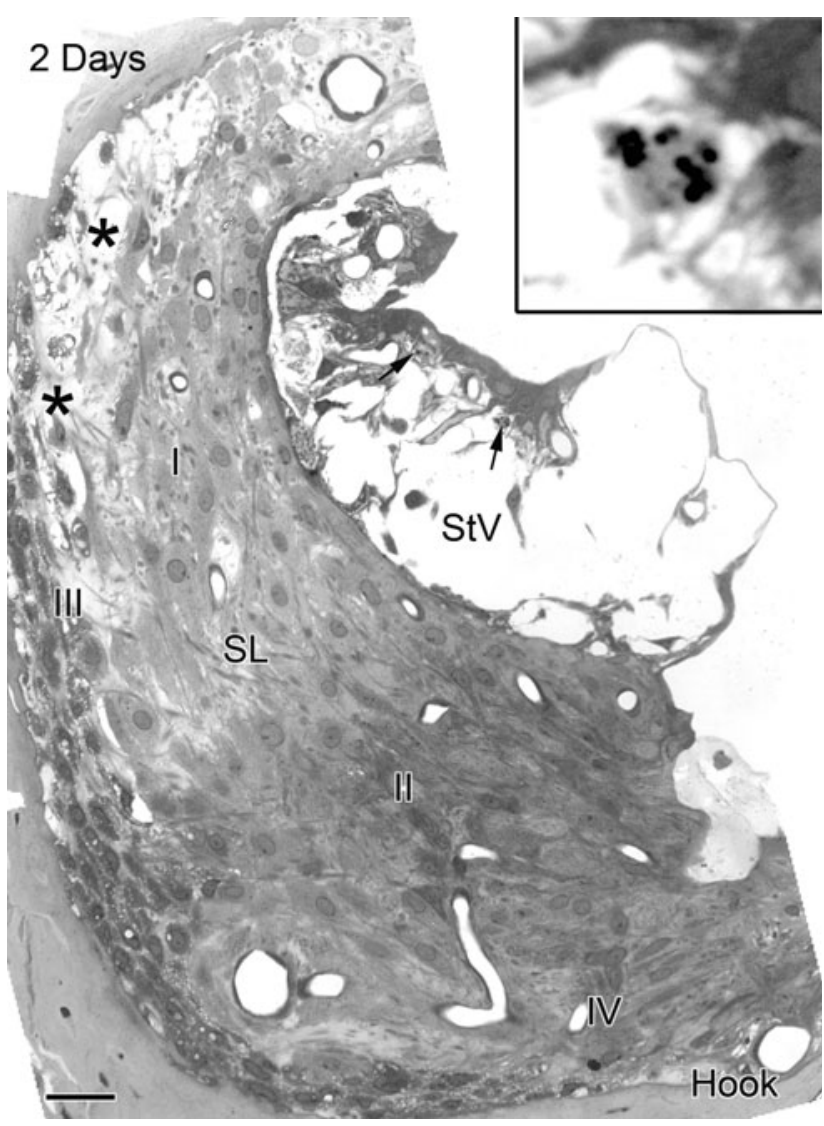

FIG. 1. Pathological changes in the lateral wall of the hook region in an ear implanted with a furosemide pump for 2 days. Wide spaces separate basal, intermediate and basal cells in the stria vascularis. Many marginal cells are intact but have lost their basal processes. Apoptotic-like bodies are evident in the nuclei of some degenerating intermediate cells (arrows). Enlarged image (see inset) shows apoptotic bodies. Increased pericellular space separates type I from type III fibrocytes (asterisks). Numerous vacuoles populate the cytosol of type III fibrocytes. The appearance of type II and IV fibrocytes is relatively normal. This cochlear region is directly adjacent to the round window where the furosemide was applied. $S L$ spiral ligament, StV stria vascularis. Scale bar $=10 \mu \mathrm{m}$.

in $\mathrm{T} 1,47 \mathrm{mV}$ in $\mathrm{T} 2$, and $49 \mathrm{mV}$ in $\mathrm{T} 3$ (Fig. 3A). $\mathrm{EP}$ values in the control ears were 101,89 , and $90 \mathrm{mV}$ in T1, T2, and T3, respectively. CAP thresholds were elevated by approximately $70 \mathrm{~dB}$ at high frequencies and $10-15 \mathrm{~dB}$ at middle and low frequencies (Fig. 3A). DPOAE amplitudes in the treated ear were markedly decreased above $12 \mathrm{kHz}$, but remained fairly robust at middle and low frequencies in view of the relatively large EP reductions in the apical and middle turns (Fig. 3B).

Pathological changes in ears implanted with a furosemide pump for 7 days were similar to those seen in animals implanted for 2-3 days, including the substantial edematous changes in the extreme basal turn in the stria vascularis (Fig. 4A). The EP values in the basal turns in one of these animals were $49 \mathrm{mV}$ for the treated ear and $98 \mathrm{mV}$ for the control ear (Fig. 4A, B). In addition, the immunostaining intensity for 


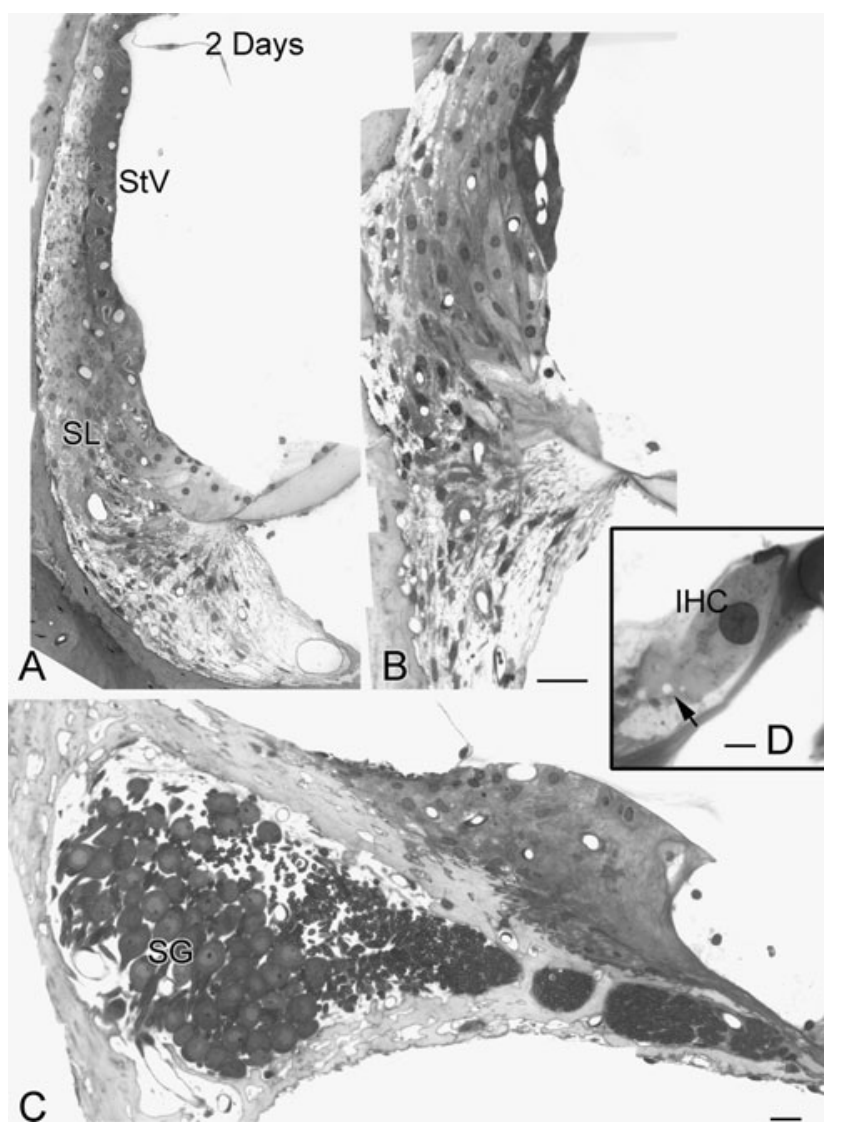

FIG. 2. Morphological features of the cochlear lateral wall in the upper basal and apical turn in the ear shown in Figure 1. A, B No pathologic changes are present in epithelial cells of the stria vascularis or fibrocytes of the spiral ligament in the upper basal and apical turns. C Spiral ganglion cell bodies and their processes in the upper basal turn appear normal. D Note that small vacuole-like spaces are sometimes seen beneath IHCs (arrow). SG spiral ganglion, IHC inner hair cell. Scale bars: A and B $15 \mu \mathrm{m}$; C $10 \mu \mathrm{m}$; D $5 \mu \mathrm{m}$.

NKCC was markedly reduced in the stria vascularis and the inferior portion of the spiral ligament in the extreme basal turn of the treated ears, as compared with young controls (Fig. 4C-E). More- over, ultrastructural observation of 7-day transplanted cochlear specimens revealed no significant pathology in auditory nerve fibers, outer hair cells, and cells in the stria vascularis (Fig. 5) outside the extreme base.

Figure 6 provides images from a cochlea exposed to furosemide for 2 weeks. In the hook region, edematous spaces were present between type I and type III fibrocytes, and small empty-appearing vacuoles filled much of type III fibrocyte's cytoplasm. In contrast to the ears exposed to furosemide for 2-3 or 7 days, the stria vascularis in the hook appeared normal in all seven ears examined. No significant histopathologic changes were seen in the spiral ganglion (Fig. 6D) and organ of Corti (Fig. 6E) in any turn. Compared with the control ear, the EP values were reduced by 25 to $33 \mathrm{mV}$ in all three turns in the treated ear in this animal. CAP threshold shifts were about $35 \mathrm{~dB}$ at high frequencies and 7 to $15 \mathrm{~dB}$ at middle and low frequencies. In addition, only a slight reduction (about $5 \mathrm{~dB}$ ) was seen in DPOAE amplitudes at low frequencies in this animal (data not shown).

In summary, major histopathologic changes in chronic-furosemide-treated ears were restricted to the extreme base (the hook region) of the cochlea. The decrease in NKCC expression in the stria vascularis and spiral ligament of the hook region was consistent with the pathological changes in the same locations. The spiral ganglion cells and sensory hair cells appeared relatively normal. DPOAEs were still relatively robust at frequencies below $10 \mathrm{kHz}$ in the treated ears, similar to those in quiet-aged gerbils (Schmiedt et al. 2002). Thus, $40 \mathrm{mV}$ declines in the EP had only about a $12 \mathrm{~dB}$ effect on DPOAE magnitudes when measured with constant-level primary tones. EP values were largely constant throughout the cochlea and ranged from 30 to $60 \mathrm{mV}$, depending on the dose (data not shown here), duration, and the individual animal.

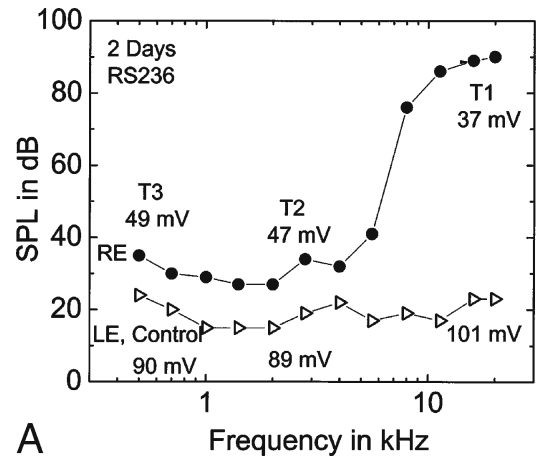

FIG. 3. Alterations of neural (CAP) responses and DPOAEs in the ear shown in Figures 1 and 2. Endocochlear potential, CAP thresholds, and DPOAE measurement in the treated (right ear, RE) and control (left ear, $L E$ ) ears. A CAP thresholds in the treated ear are elevated by about $15 \mathrm{~dB}$ at frequencies below $4 \mathrm{kHz}$ and by as much as $70 \mathrm{~dB}$ at higher

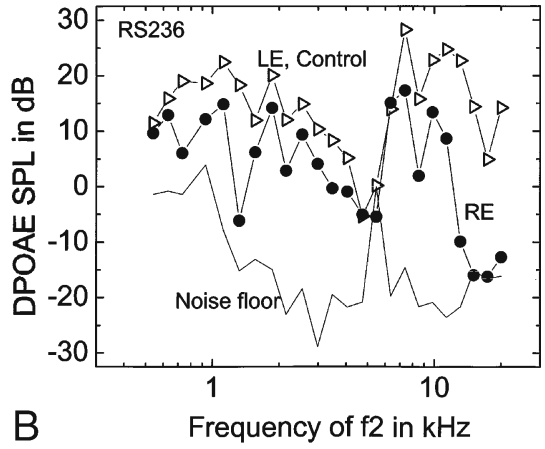

frequencies as compared with the control ear. EP values declined by about $60 \mathrm{mV}$ from control values in the basal turn (T1) and about $40 \mathrm{mV}$ in the middle (T2) and apical (T3) turns. B DPOAE amplitudes were reduced, but remained relatively robust in the treated ear except above $12 \mathrm{kHz}$. Dotted curve is the acoustic noise floor. 


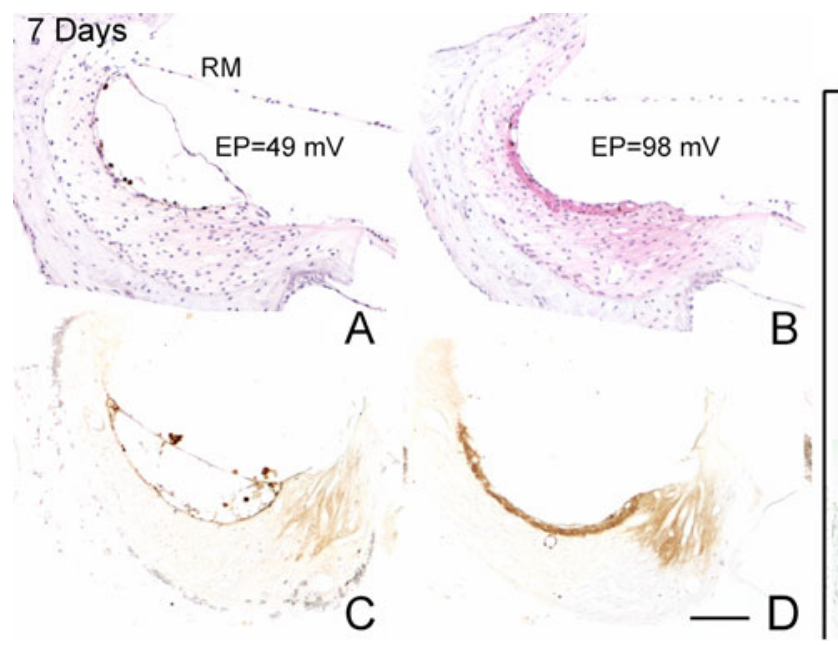

FIG. 4. Reduction of immunoreactive NKCC in the stria vascularis of the extreme basal turn in an ear implanted with a furosemide pump for 7 days. A Hematoxylin and eosin stained radial section through the basal turn of the furosemide-treated right ear shows pathological changes in the stria vascularis. B Same region of the lateral wall in the untreated left ear has a normal appearance. The EP values obtained from $\mathrm{T} 1$ in treated and untreated ears were 49 and

\section{Cochlear adaptation to chronic-furosemide} treatment in young-adult gerbils

The histopathologic changes in the hook regions of the implanted ears described above were mostly seen at $2-$

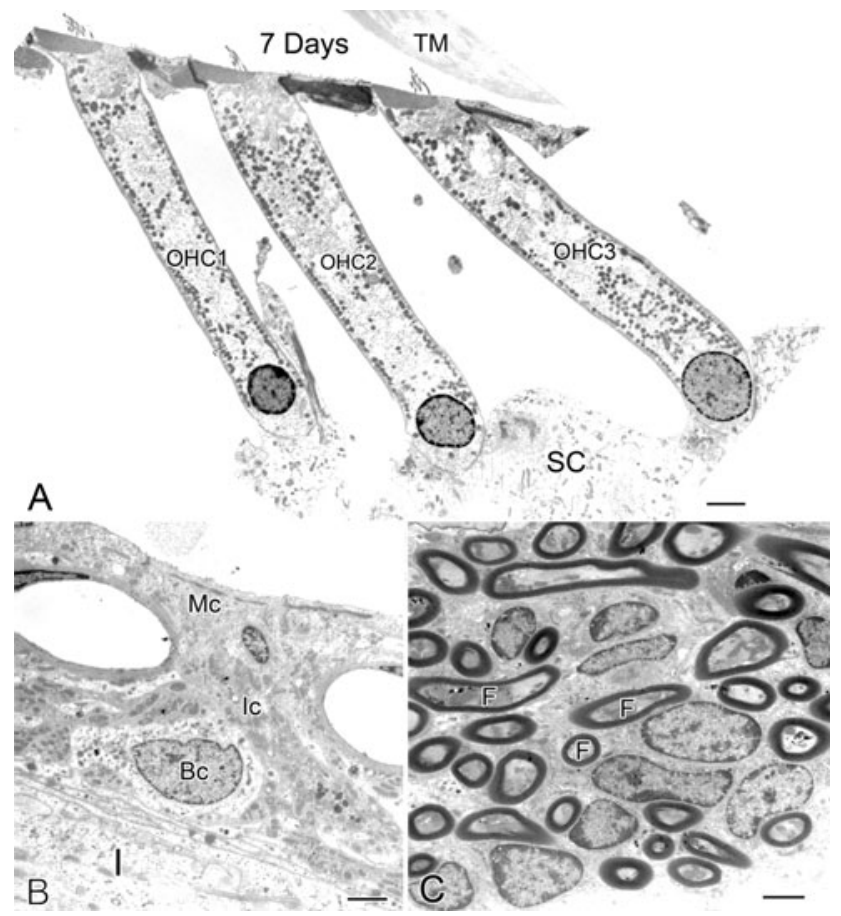

FIG. 5. Ultrastructural features of the outer hair cells, stria vascularis, and auditory nerve fibers in an ear implanted with a furosemide pump for 7 days. A Three outer hair cells (1-3) in the middle turn appear healthy. SC supporting cells. B Marginal (MC), intermediate $(I C)$, and basal $(B C)$ cells in the stria vascularis in the apical turn have a normal morphologic appearance. C Auditory nerve fibers $(F)$ within the osseous spiral lamina have a normal appearance. Scale bars: A $4 \mu \mathrm{m}$; B, C $2 \mu \mathrm{m}$.

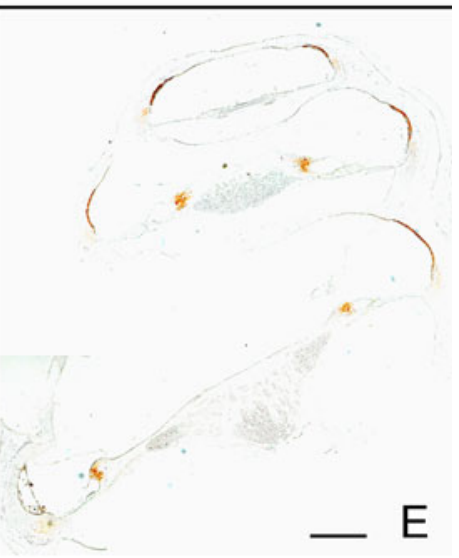

$98 \mathrm{mV}$, respectively. C, D Images obtained from sections adjacent to those in $\mathbf{A}$ and $\mathbf{B}$ show a remarkable loss of immunoreactive NKCC in the stria vascularis and inferior spiral ligament of the treated ear in this region near the round window as compared with the control ear. E Strong immunostaining for NKCC remains in the apical, middle, and upper basal turns of the treated ear. Scale bars: A-D $20 \mu \mathrm{m} ; \mathbf{E}$ $50 \mu \mathrm{m}$.

3 days and 7 days of treatment. Surprisingly, continued exposure to furosemide did not cause more severe damage but rather resulted in the return of the stria vascularis to an almost normal morphology at $2-4$ weeks of treatment (Fig. 6). The level of edema in the basal lateral wall of these treated ears was ranked 2-3 days $>$ 7 days $>2-4$ weeks. Moreover, the changes in mean EP values in Figure 7A clearly show that the young gerbil ear is able to functionally adapt to a chronic-furosemide insult. The mean EP values in T1, T2, and T3 of treated ears were 32,36 , and $37 \mathrm{mV}$ for $2-3$ day pump animals, 49,56 , and $50 \mathrm{mV}$ for 1-week pump animals, and 66, 69, and $63 \mathrm{mV}$ for $2-4$ week pump animals (Fig. 7A). The EP values in all three cochlear turns show the same rank order: $2-3$ day $<7$ days $<2-4$ weeks.

CAP threshold shifts also demonstrate that the cochlea is able to adapt to chronic-furosemide insult (Fig. 7B). After 2-3 days and 7 days of exposure, CAP thresholds were greatly elevated at high frequencies and shifted by about $15 \mathrm{~dB}$ at lower frequencies with no significant differences found between the 2-3 and 7 day groups across all frequencies tested (ANOVA, $p>0.05$ ). A marked recovery of CAP response occurred in the 24 week group. The differences in CAP thresholds from 4 to $11.3 \mathrm{kHz}$ between the 1 week and $2-4$ week implanted groups, and between 2-3 day and 2-4 week implanted groups are significant, respectively (ANOVA, $p<0.05$ ). However, no significant differences were found in CAP thresholds among the three groups at 16 and $22.6 \mathrm{kHz}$ (ANOVA and post hoc comparisons, $p>0.05$ ). It should be noted that the stability of the furosemide and its rate of release from the pump were tested after 4 weeks in two animals in situ and were similar to those of the 2-3 day exposure (see Materials and methods). 


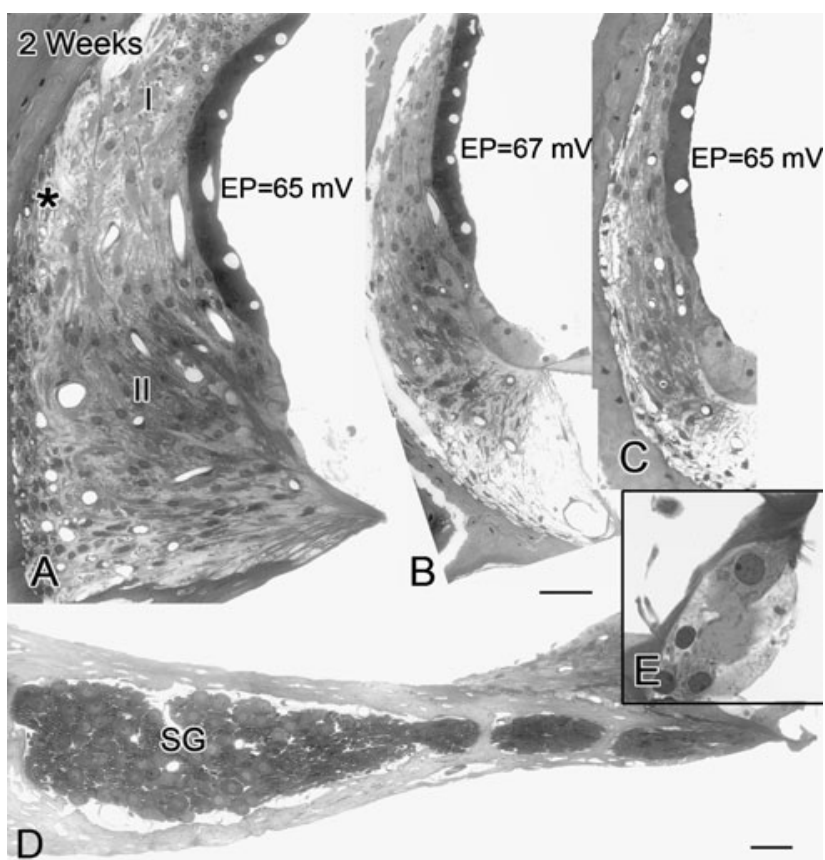

FIG. 6. Cochlear morphology in an ear implanted with a furosemide pump for 2 weeks. A Edematous changes are absent in the stria vascularis of the hook region, whereas intercellular edema remains between type I and III fibrocytes. Note the cochlear turn in A is slightly more apical than that shown in Figure 1. Numerous vacuoles are present in the cytosol of type III fibrocytes (large asterisk). B, C The stria vascularis and spiral ligament in the middle and apical turns show no significant pathologic changes. D Spiral ganglion cell bodies and their processes in the extreme basal turn of this furosemide-treated ear also show no pathologic change. $\mathbf{E}$ The hair cells have normal appearance. Scale bars: $15 \mu \mathrm{m}$.

CAP responses and EP values in ears exposed to furosemide for 7 days are similar to those of quiet-aged gerbils

CAP thresholds and EP values obtained from the three treated groups implanted with furosemide pumps for 2-3 days, 7 days, and 2-4 weeks were compared with those previously obtained from the

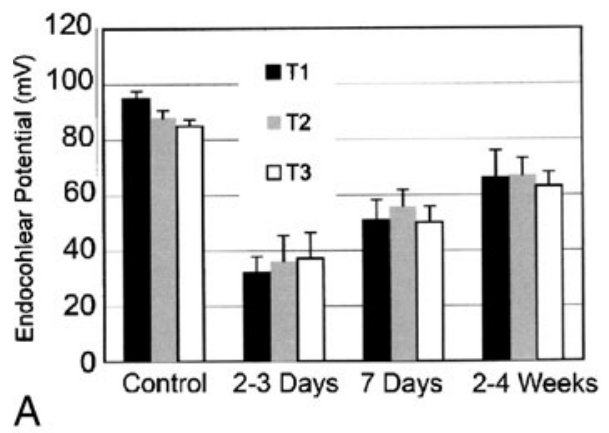

FIG. 7. Cochlear adaptation to chronic furosemide exposure. A Mean EP values obtained from turns T1, T2, and T3 are presented as mean \pm SEM ( $n=5$ for a $2-3$ day group; $n=15$ for a 1 week group; $n=7$ for a $2-4$ week group; $n=15$ for young controls). The EP values increase with longer exposure times in all the three cochlear turns. B Mean CAP thresholds obtained from the same ears as shown in $\mathbf{A}$. two groups of quiet-aged gerbils (Fig. 8). These two groups of aged animals included 27 gerbils aged 36 months and ten gerbils aged 38 to 45 months.

The mean $\mathrm{EP}$ values in $\mathrm{T} 1$ were $67.6 \mathrm{mV}$ for the 36 month-old group and $45.1 \mathrm{mV}$ for the 38-month-old group (Fig. 8). The EP values of 7 day $(48.9 \pm 7.4 \mathrm{mV}$ ) and $2-4$ week $(66.2 \pm 10 \mathrm{mV})$ furosemide-treated ears were within the range of mean EP values in the aged gerbils. The mean EP of the 2-3 day exposed ears $(32.2 \pm 5.8 \mathrm{mV})$ was considerably lower. The mean CAP threshold curves for the two groups of aged gerbils are plotted in Figure 8. An increasing shift at both high and low frequencies was seen in the 38month-old group compared with the 36-month-old group (Schmiedt et al. 2002). CAP thresholds for the 2-3 and 7 day implanted animals, but not for the 24 week animals, were within the ranges of those in the aged groups (Fig. 8). At higher frequencies above $1.4 \mathrm{kHz}$, the thresholds of the $2-4$ and 7 day exposed ears were close to those from 38-month-old ears. At frequencies below $2 \mathrm{kHz}$, the thresholds were similar to those from the 36-month-old group. The increased threshold shift at low frequencies seen in the older group is probably due to the increased outer hair cell loss in the apex seen in these very old animals (Tarnowski et al. 1991). EP values and CAP threshold profiles across frequency seen in gerbil ears exposed to furosemide for 7 days closely resemble those in quiet-aged gerbils, thereby forming the basis of the furosemide model of age-related hearing loss (Schmiedt et al. 2002; Schmiedt 2009).

Response properties of auditory nerve fibers in furosemide-treated ears are similar to those in quiet-aged ears

CAP I/O functions, single-unit recordings for primary auditory nerves, and CAP recovery functions were determined in the ears exposed to furosemide for

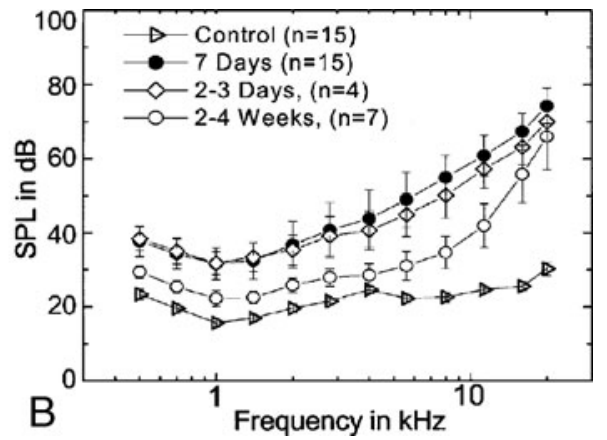

Thresholds of both the 2-3 day and 1 week exposed groups were elevated by about $40 \mathrm{~dB}$ at high frequencies and 15-20 dB at middle and low frequencies compared with those of control ear. However, thresholds in the 2-4 week group were only elevated by about $5 \mathrm{~dB}$ at low and middle frequencies, whereas the thresholds at high frequencies approached to those of the 2-3 day and 7 day groups. 


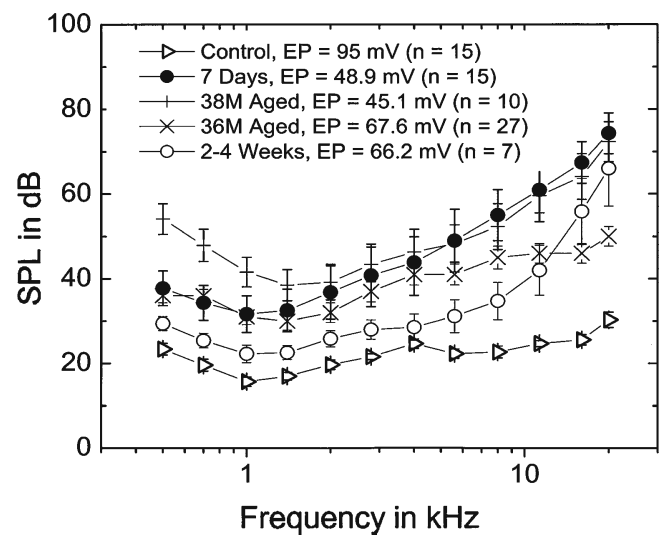

FIG. 8. Similarities in CAP thresholds and EP values in furosemidetreated and quiet-aged ears. Mean CAP thresholds and EP values in gerbils treated for 7 days compared with those from two groups of quiet-aged gerbils. Mean data are shown for the 7 day furosemide group $(n=15)$, the 36 -month-old group $(n=27)$, and the $38-$ 45-month-old group $(n=10)$.

7 days. CAP I/O functions allow examination of supra-threshold CAP amplitudes to assess the gross activity of the primary auditory nerves at high signal levels. Peak-to-peak amplitudes of the first negative and positive peaks in each CAP waveform were measured vs. stimulus level at 1, 2, 4, 8, and $16 \mathrm{kHz}$. The mean amplitudes of the neural I/O functions from the 7 day furosemide pump animals $(n=11)$ are illustrated in Figure 9. Both the maximum amplitudes and slopes of the $\mathrm{I} / \mathrm{O}$ functions were reduced dramatically at $2,4,8$, and $16 \mathrm{kHz}$ compared with the controls along with elevated thresholds. These results are similar to those observed in gerbils aged
35-37 months in quiet (Hellstrom and Schmiedt 1990), suggesting that it is the EP reduction per se that is responsible for the decreased CAP response, not a loss of spiral ganglion neurons, given that the furosemide-treated animals had morphologically normal spiral ganglion cells. These CAP I/O functions are similar to those obtained from quiet-aged gerbils (Schmiedt et al. 2002; Schmiedt 2009).

Single-unit recordings from primary auditory fibers were recorded from 11 young controls. As shown in Figure 10A, CF thresholds tend to increase markedly as SR falls below 18 spikes per second. This result is similar to our previous observations in normal young gerbils (Fig. 10C) and previously published data in normal cats (Kiang et al. 1970, 1976; Liberman 1978). In this study, the treated gerbils were implanted with an osmotic pump for 7 days. After 7 days of furosemide exposure, the $\mathrm{CF}$ thresholds for fibers with SR $>18$ spikes per second were shifted upward so that most thresholds were between 5 and $90 \mathrm{~dB}$ SPL (Fig. 10B) rather than between 5 and $30 \mathrm{~dB}$ SPL as in the normal young control (Fig. 10A). This pattern of CF threshold shift relative to SR in the chronicfurosemide-treated ears is similar to that observed in quiet-aged gerbils showing an upward shift of the CF thresholds in the fibers with SR $>18$ spikes per second (Fig. 10D). The data in Figure 10C, D were taken from the same data pool of a previous large-scale study in aged gerbils (Schmiedt et al. 1996).

The distribution of SR as a function of fiber CF for young and chronic-furosemide gerbils is shown in Figures 11 and 12 . The use of the $6 \mathrm{kHz}$ as a cutoff frequency is based on the statistics of this study and
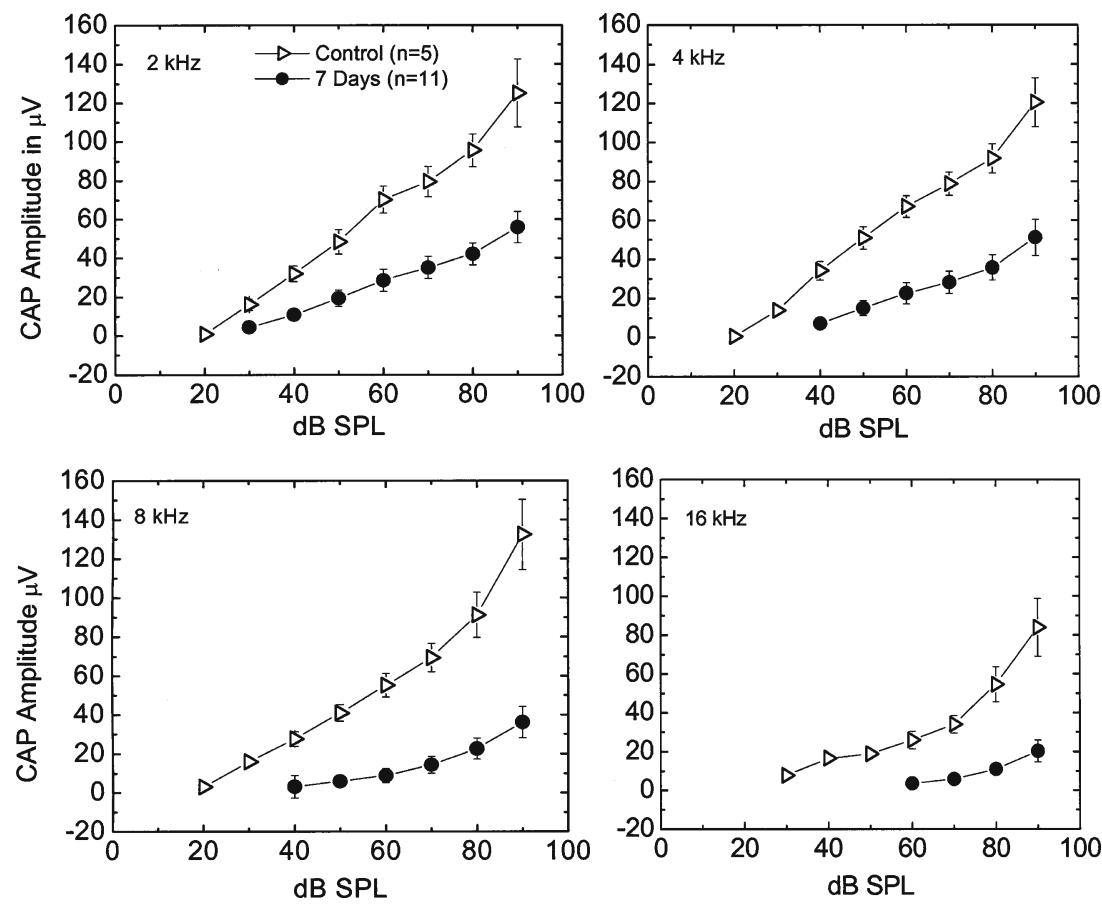

FIG. 9. Alterations of supra-threshold neural responses in furosemide-treated ears. Mean CAP I/O functions obtained with 2, 4, 8, and $16 \mathrm{kHz}$ probe tones from control ears $(n=5)$ and ears treated with furosemide for 7 days $(n=11)$. Error bars are SEM values. Note that $\mathrm{I} / \mathrm{O}$ functions from furosemide-treated gerbils have shifted thresholds and are flattened at all test frequencies. Because these animals were young with no hair cell and ganglion cell pathologies, it is most probably the reduced EP that is causing these shifts. 

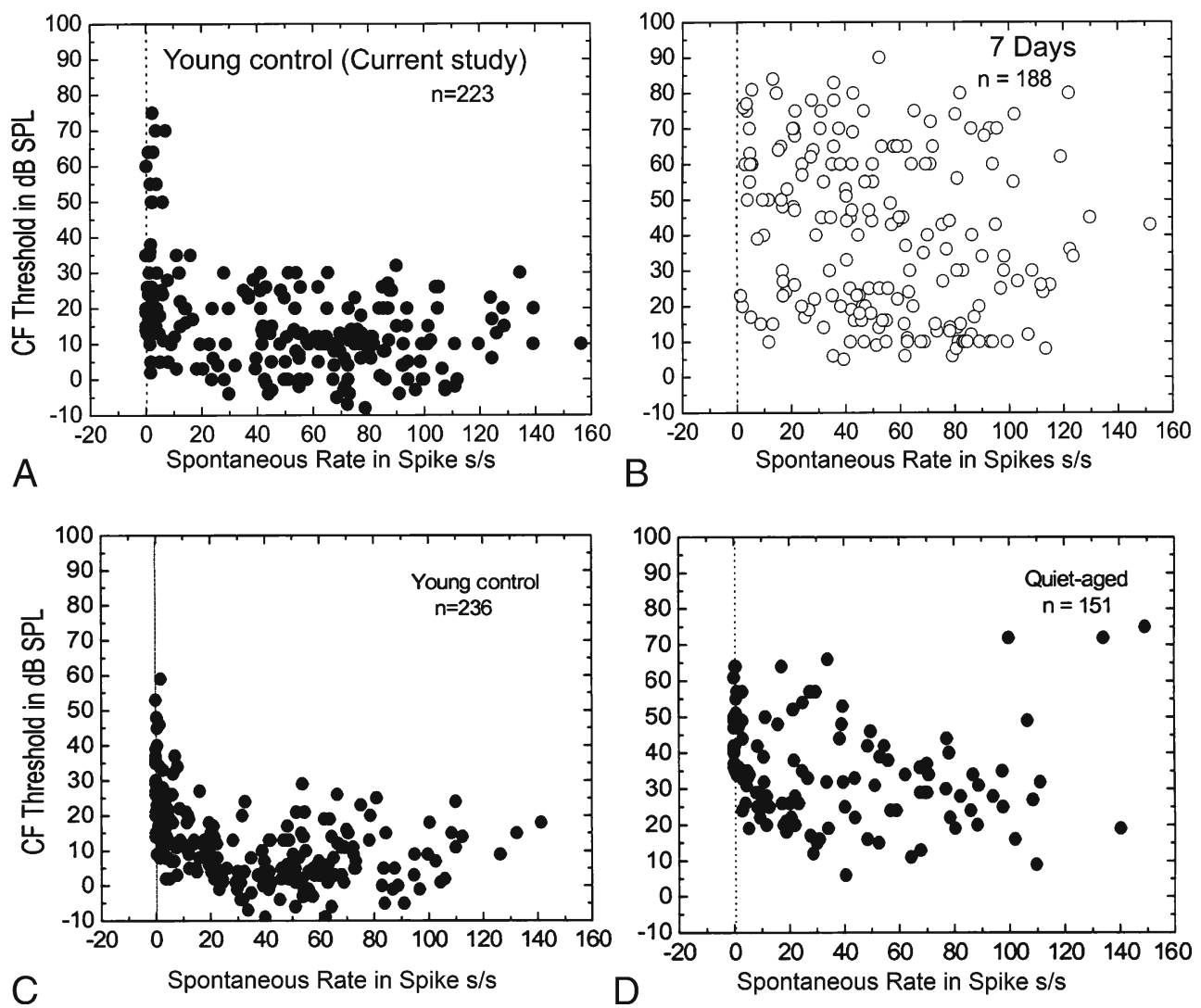

FIG. 10. Alterations of $\mathrm{CF}$ thresholds and spontaneous rates in furosemide-treated ears. A CF threshold is plotted against spontaneous rate (SR) for 223 fibers from 11 young gerbils. B CF threshold is plotted against SR for 188 fibers from 15 furosemide-treated ears. C CF threshold is plotted against SR for 236 fibers from 11 young

gerbils. D CF threshold is plotted against SR for 151 fibers from ten quiet-aged gerbils. Note that data shown in panels $\mathbf{C}$ and $\mathbf{D}$ have been replotted from a previous aging study in gerbils (Schmiedt et al. 1996). It is clear that differences in low-SR and high-SR thresholds are greatly reduced in the treated and aged ears.

our previous study (Schmiedt et al. 1996). In young controls, $42.9 \%$ of the fibers contacted with $\mathrm{CFs} \geq$ $6 \mathrm{kHz}$ were low-SR fibers whereas in furosemidetreated gerbils, this percentage dropped to $15.2 \%$ (Figs. 11A, B and 12A). This difference was statistically significant (chi-square, $p<0.01$ ). Conversely, the percentages of low-SR fibers at $\mathrm{CFs}<6 \mathrm{kHz}$ were $20.6 \%$ and $16.9 \%$ in young control and furosemide-treated gerbils, respectively, with no significant difference between the two groups (Figs. 11A, B and 12B). These results are similar to our previous results in aged gerbils showing a significant loss of activity of low-SR auditory nerve fibers with $\mathrm{CFs} \geq 6 \mathrm{kHz}$.

\section{Effect of furosemide on CAP recovery function}

Unlike the cat, the gerbil is not an ideal model for observations of populations of auditory neurons (Schmiedt et al. 1999, Schmiedt et al. 1996; Ohlemiller and Siegel 1994). The single-fiber data in Figures 11 and 12 were obtained from 11 young control and 15 furosemide-treated ears. The number of fibers recorded in control and furosemidetreated animals ranged from four to 85 per animal, thus it is possible that sampling error or other unknown biases may be present in these single-fiber data. To further examine the activities of low-SR auditory nerve fibers after furosemide exposure, we employed a method developed by Relkin et al. (1995) using the recovery from a prior conditioning stimulus of the auditory whole-nerve response, CAP response. The CAP is an evoked population response that can be free from the sampling errors that may be present in single-fiber recording procedures. The recovery of CAP responses after a conditioning tone is an effective method for measuring the population ratio of active low- and high-SR fibers (Murnane et al. 1998; Schmiedt et al. 1996; Lang et al. 2002; Taberner and Liberman 2005). Low-SR fibers recover from prior stimulation more slowly than high-SR fibers, yielding two components in CAP recovery curves. The first component is the recovery of both the high- and lowSR groups, whereas the later component reflects only the low-SR recovery.

We measured the CAP recovery functions in five gerbils implanted with furosemide pumps for 7 days (Fig. 13). Regression analysis showed a significant change of slope for points above and below $\Delta T=$ 

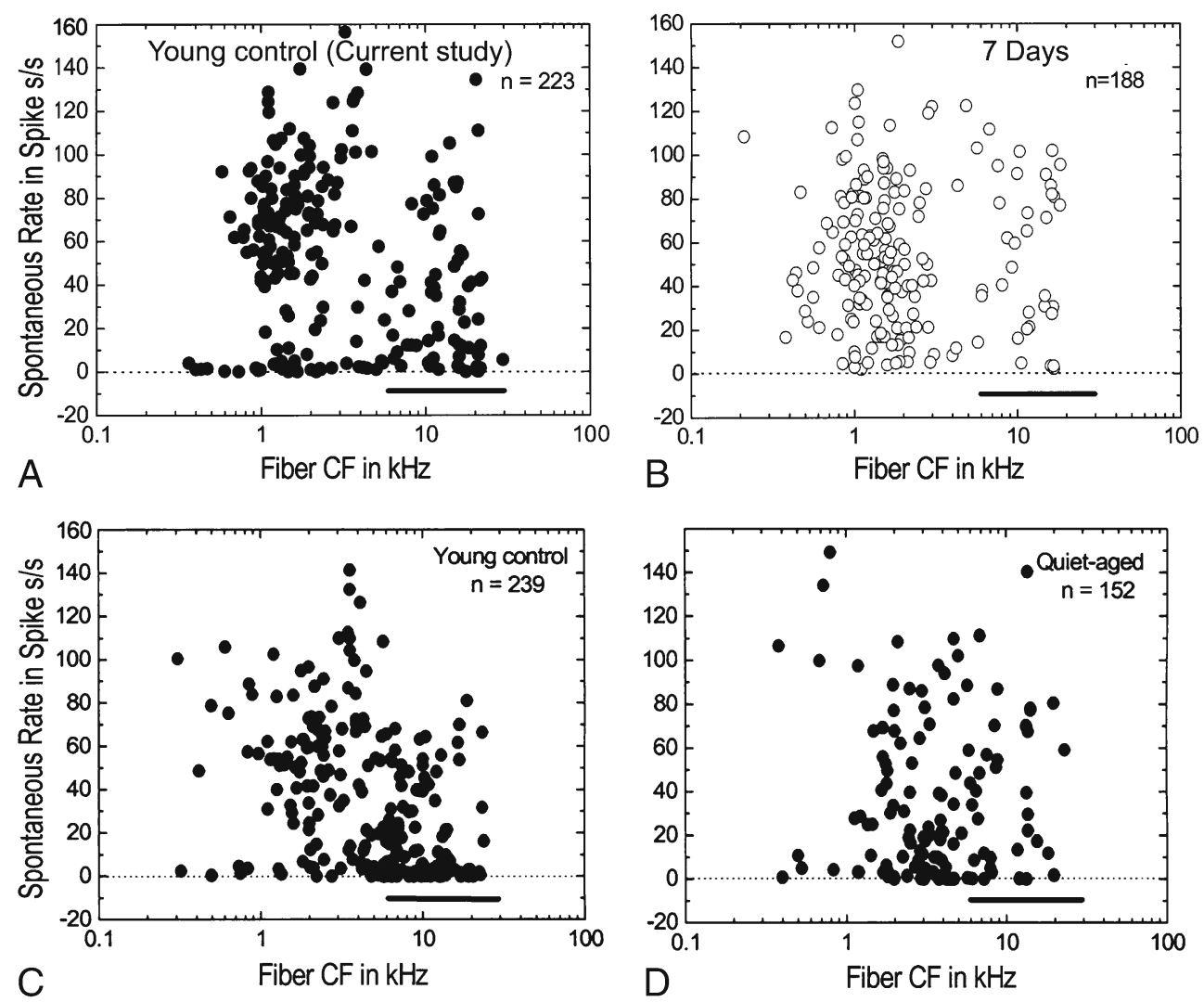

FIG. 11. Alterations of the spontaneous rate profile in furosemidetreated ears. A SR is plotted against CF for 223 fibers from 11 young control gerbils. Note the large number of low-SR fibers at $\mathrm{CFs} \geq$ $6 \mathrm{kHz}$ (heavy bar). B SR is plotted against CF for 188 fibers from 15 furosemide-treated gerbils. There is a relative absence of low-SR fibers with high CFs in the furosemide-treated group (heavy bar). All furosemide-treated gerbils received $5 \mathrm{mg} / \mathrm{ml}$ furosemide for 7 days. C

$130 \mathrm{~ms}(p<0.01)$ at $2,4,8$, and $16 \mathrm{kHz}$ frequencies in both treated and control animals, indicating the presence of fast and slow recovery components. There was no significant difference in mean CAP recovery curves at 2 and $4 \mathrm{kHz}$ between the furosemide-treated and young control group (ANOVA, $p>0.05$ ). However, at 8 and $16 \mathrm{kHz}$, the furosemide-treated cochleas had a larger decrement and a steeper slope at $\Delta T<130 \mathrm{~ms}$ than the young controls $(p<0.05)$. At $\Delta T>130 \mathrm{~ms}$, there were no significant differences between the furosemide and young control data $(p>0.05)$. These results indicate that the recovery of the CAP response at high frequencies following a conditioning stimulus was faster in furosemide-treated ears than control ears. Thus, these CAP data agree with the population data obtained from single auditory nerve fibers shown in Figures 10, 11, and 12 and support the finding that fewer low-SR fibers are active in the furosemide-treated gerbils at high CFs. These results also are the same as those seen in quiet-aged gerbils (Schmiedt et al. 1996), suggesting that EP loss can have a direct impact on the responsiveness of select groups of auditory fibers, specifically the low-SR fibers with $\mathrm{CFs} \geq 6 \mathrm{kHz}$.

SR is plotted against CF for 239 fibers from a previous group of 11 young control gerbils. Again, note the large number of low-SR fibers with CFs $\geq 6 \mathrm{kHz}$ (heavy bar). D SR is plotted against CF for 151 fibers from ten aged gerbils. Note the relative absence of low-SR fibers at $\mathrm{CFs} \geq 6 \mathrm{kHz}$ (heavy bar) like that seen with furosemide treatment. The data in panels $\mathbf{C}$ and $\mathbf{D}$ were taken from a previous study on aged gerbils (Schmiedt et al. 1996).

\section{DISCUSSION}

An important question left unanswered from our previous studies in quiet-aged gerbils was whether the apparent loss or decrease in activity of low-SR auditory nerve fibers with high CFs was a direct consequence of the chronically reduced EP seen in those older animals (Schmiedt et al. 1996). Here, we have shown that in the chronic-furosemide model of "metabolic" presbyacusis: (1) the morphological appearance of the cochlea is relatively normal with the exception of pathological changes in the lateral wall in the extreme basal region; (2) the cochlea can adapt to furosemide application over time; (3) DPOAE amplitudes are only moderately decreased across frequency, when obtained with constant low level (50 dB) primaries; (4) a chronic decline in the EP can differentially decrease the activity of low-SR primary auditory neurons with $\mathrm{CFs} \geq 6 \mathrm{kHz}$; and (5) CAP thresholds, I/O functions and recovery curves, and SR profiles across fiber CF are very similar to those in quiet-aged gerbils. Based on the striking similarities in the physiological responses in furose- 


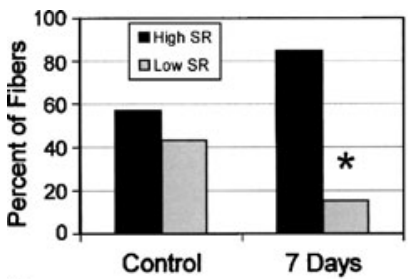

A Fiber $\mathrm{CFs} \geqslant 6 \mathrm{kHz}$

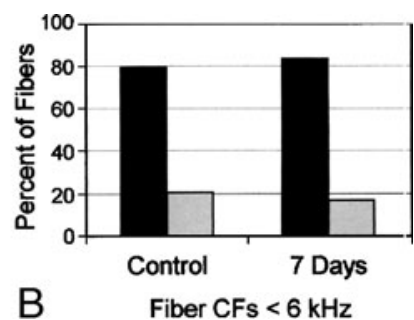

FIG. 12. Bar graphs of the spontaneous rate data from the same fiber population shown in Figure 11. Data include 223 fibers from 11 young gerbils and 188 fibers from 15 furosemide-treated gerbils. A The percent of auditory nerve fibers with $\mathrm{CFs} \geq 6 \mathrm{kHz}$ contacted with high-SR (dark bars) or low-SR (light bars). In young controls, $\sim 43 \%$ of the fibers contacted are low-SR fibers; in furosemide-treated gerbils, this percentage drops to $\sim 15 \%$. The percentages of low-SR fibers are significantly different between the young and the furosemide-treated gerbils $(p<0.01$, chi-square test). B The percent of auditory nerve fibers with CFs $<6 \mathrm{kHz}$ contacted with high-SR (dark bars) or low-SR (light bars) as shown in Figure 11B. In young controls, $\sim 21 \%$ of the fibers contacted with $\mathrm{CFs}<6 \mathrm{kHz}$ were low-SR fibers; in furosemidetreated gerbils, this percentage was $\sim 17 \%$. There were no significant difference at CFs $<6 \mathrm{kHz}$ in the percentages of low-SR fibers between the young and the furosemide-treated gerbils ( $p>$ 0.05, chi-square test).

mide-treated and quiet-aged gerbils, we conclude that a chronic reduction in the EP is responsible for much of the hearing loss in metabolic presbyacusis.

Although many factors contribute to age-related loss of auditory function, it is generally believed that the degeneration and loss of various inner ear cell

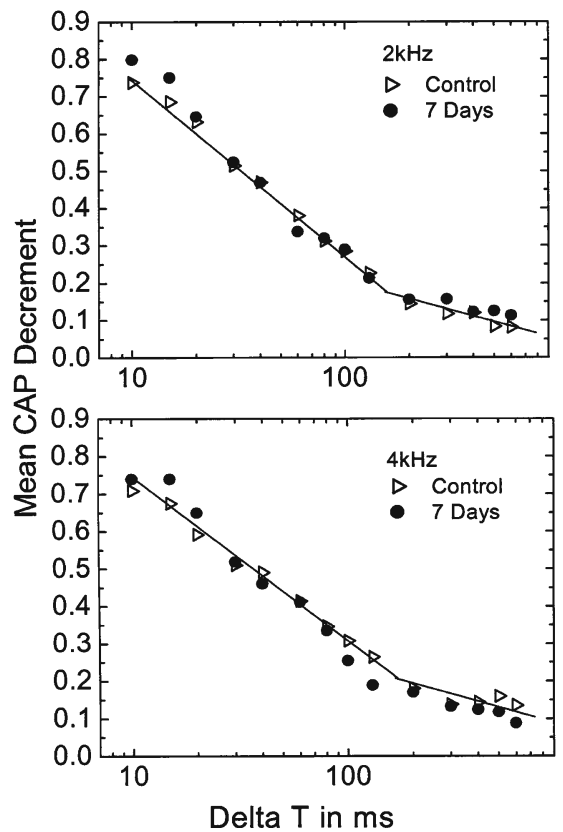

FIG. 13. CAP recovery functions in furosemide-treated ears. Left panels: Mean CAP recovery curves in terms of the normalized decrement as a function of $\Delta T$ at frequencies of 2 (top) and $4 \mathrm{kHz}$ (bottom). The data are from five ears treated with furosemide for 7 days and five young control ears. All furosemide-treated gerbils were implanted with a $5 \mathrm{mg} / \mathrm{ml}$ furosemide pump for 7 days. There were no significant differences between the furosemide-treated and control groups at these frequencies. Regression analysis shows a significant types is the major cause of presbyacusis. These cell types include sensory hair cells, spiral ganglion neurons, and non-sensory cells such as those comprising the stria vascularis and fibrocytes in the cochlear lateral wall. These latter cell types are specialized to produce the electrochemical gradients that drive the auditory transduction process. Previous studies have shown that age-related hearing loss in quiet-reared gerbils is commonly associated with pathologies in the lateral wall and stria vascularis, resulting in a chronically reduced EP (Schulte and Schmiedt 1992; Gratton et al. 1996, 1997; Spicer et al. 1997; Spicer and Schulte 2002). Neuronal loss in Rosenthal's canal is also seen in aged gerbils (Keithley et al. 1989; Slepecky et al. 2000; Suryadevara et al. 2001; Mills et al. 2006). However, because of the complexity of histopathological changes in aged cochleas, it has been difficult to isolate the role of a chronic reduction in the EP in producing functional changes in auditory response properties. The age-related decrease in spiral ganglion neuron density of around $17 \%$ throughout the cochlea in aged gerbils makes this problem particularly challenging (Mills et al. 2006). To overcome this difficulty, we developed a young animal model with a reduced EP and histological changes limited to the extreme base of the cochlea. The histopathologic data presented here provide evidence that the controlled delivery of furosemide via the round window in the gerbil using
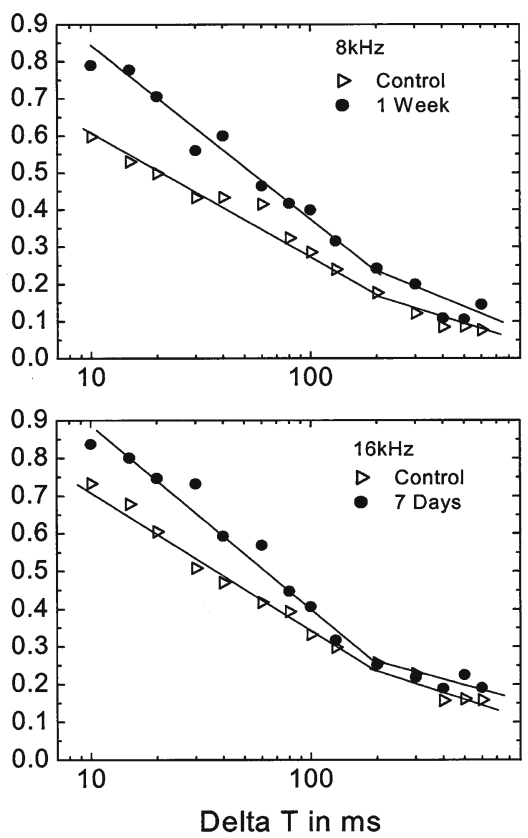

change of slope for points above and below $\Delta T=130 \mathrm{~ms}(p<0.01)$. Right panels: Mean CAP recovery curves obtained at 8 (top) and $16 \mathrm{kHz}$ (bottom) from the same gerbils show in left panels. At these higher frequencies, there are significant differences between the furosemide-treated and untreated groups. The recovery time constant is significantly shorter in the treated group, indicating a decreased number of active low-SR fibers compared with that in normal controls, corroborating the single fiber data shown in Figure 12. 
an osmotic pump results in edema of the cochlear lateral wall and loss of strial intermediate cells, but only in the extreme base, with the remaining lateral wall cells largely intact. There are also little or no detectable histopathologic changes in other cochlear cell types including spiral ganglion neurons, although small vacuole-like spaces were occasionally seen beneath IHCs. Whether these spaces reflect some pathological changes in nerve endings or are fixation artifacts requires further study.

Furosemide-induced declines in the EP are thought to be the result of the inhibition of NKCC in the basolateral membrane of the marginal cells in the stria vascularis (Sakaguchi et al. 1998; Wangemann et al. 1995). NKCG is an important protein that aides the active transport of sodium, potassium, and chloride into and out of cells. NKCC has also been shown to be involved in cell swelling in several neurological disorders (Jayakumar et al. 2008). In the mammalian cochlea, NKCC protein is expressed at high levels in strial marginal cells and in type II, IV, and V lateral wall fibrocytes (Crouch et al. 1997; Sakaguchi et al. 1998). A remarkable loss of immunoreactive NKCC is seen in the stria vascularis and fibrocytes in the inferior spiral ligament in the hook region of the ears exposed to furosemide for 7 days. This finding is highly consistent with pathological changes in the same region and indicates a cellular injury caused by furosemide exposure. The finding that functional changes in response to early (2-7 days) chronic furosemide exposure occurred mainly at very high frequencies also is consistent with the pathology of the cochlear lateral wall in the hook region. The hook region is adjacent to the round window where furosemide is applied via the implanted osmotic pump. It would be reasonable to predict that this local effect would change if the furosemide pump was implanted in the apical turn. However, longitudinal gradients of antioxidants as well as the kinetics of the cochlear fluids would also be expected to affect the pattern of furosemide damage (Rarey and Yao 1996; Wagner et al. 2005; Salt and Ma 2001; Salt 2005).

Ears exposed to furosemide for 7 days showed a constant CAP threshold shift below about $4 \mathrm{kHz}$, coupled with an increasing loss at higher frequencies. This profile is probably a refection of the sensitivity or gain of the cochlear amplifier as related to EP values, with a maximum gain of about $20 \mathrm{~dB}$ at low frequencies and an increasing gain of up to 60 $70 \mathrm{~dB}$ at high frequecies (Sewell 1984; Ruggero and Rich 1991; Cooper and Rhode 1992; Schmiedt et al. 2002; Schmiedt 2009).

The relatively robust DPOAE's at frequencies below about $12 \mathrm{kHz}$ most probably result from the use of constant-level primaries. It is likely that DPOAE thresholds would have provided a better measure of the reduced gain of the OHC amplify in response to a chronically lowered EP (Mills et al. 1990).

An unexpected finding was that the young-adult gerbil ear can adapt to a chronic-furosemide insult. The recovery of mean CAP thresholds and EP values in ears treated for 2-4 weeks relative to those treated for 2-7 days (Fig. 7) clearly demonstrates a functional improvement in these ears. The repair or replacement of lateral wall fibrocytes and the recovery of the stria vascularis may play a major role in the cochlear adaptation phenomenon. Dividing cells have been reported in the spiral ligament of both normal and injured ears in gerbils and mice (Roberson and Rubel 1994; Yamashita et al. 1999). Our previous studies have shown that furosemide treatment increases the number of BrdU-positive cells in the spiral ligament of young-adult gerbil ears (Lang et al. 2003). The present results clearly demonstrate that the stria vascularis has the ability to adapt to chronic furosemide exposure and repair itself. The ability of stria to repair itself after injury, in particular the replacement of intermediate cells, has been previously documented (Conlee et al. 1994; Hirose and Liberman 2003).

Auditory nerve fibers in the cat consist of separate populations having low and high SRs (Kiang et al. 1965; Liberman 1978). Auditory fibers with small diameters, high thresholds, and low SRs are located on the modiolar side of the inner hair cell. Large diameter fibers with lower thresholds and high SRs are located predominantly on the pillar side of the inner hair cell (Liberman and Oliver 1978). In the gerbil, the low-SR fibers do not seem to be spatially segregated as seen in cats and do not disappear with age (Suryadevara et al. 2001). The chronic-furosemide model of presbyacusis yields a reduction in the EP similar to that observed in quiet-aged gerbils in an otherwise relatively healthy cochlear environment. The data shown here support the hypothesis that the loss of activity of the low-SR, high-CF fibers results from the lowered EP and not from degeneration of the fibers. In other words, the low-SR, high-CF fibers may become inactive at normal levels of acoustic stimulation when the EP is reduced by $20-40 \mathrm{mV}$ as is in the case of aged gerbils.

A decreased EP due either to chronic exposure to furosemide or to aging may deprive basal inner hair cells of the higher level of depolarization needed to activate low-SR synapses, thereby elevating the threshold of low-SR high-CF fibers in the cochlear base (Figs. 11, 12, and 13). Our results differ somewhat from those of a previous study in the cat which showed that acutely administered furosemide decreased the spontaneous discharge rate of all auditory nerve fibers (Sewell 1984). A possible reason for this difference is that high-SR synapses may be able to adapt to a chronic decrease in the EP, thereby 
restoring their SR to normal values, but with a corresponding loss of threshold. Conversely, the lowSR, high-CF synapses may not be able to adapt to the lowered EP with regard to SR and threshold, yielding very high acoustic thresholds for these fibers. An interesting experiment would be to use an electric shock as a search stimulus, rather than an acoustic noise stimulus that was used here.

A differential effect in thresholds was also found by Sewell (1984) whereby low-SR fibers were more sensitive than high-SR fibers to a temporary EP reduction in cats acutely treated with intravenous furosemide. The spontaneous activity of auditory fibers is modulated by the rate of release of transmitter from the inner hair cells, which is modulated by the presynaptic membrane potential (Sewell 1984; Mroz and Sewell 1989). Considerable evidence suggests that the membrane potential of the hair cell is dependent on the EP (Davis 1958, 1965; Honrubia and Ward 1969; Russell 1983). Thus, a decline in the EP may affect the activity of low-SR, high-CF fibers more than the high-SR, high-CF fibers. Metabolic presbyacusis may very well have a hidden consequence of effectively eliminating the low-SR fiber system at high frequencies.

Taken together, the physiological changes in the chronic-furosemide model mimic those seen in quietaged gerbil cochleas at the single-fiber and fiber population levels and support the assumption that the major cause of age-related changes in peripheral auditory function in the gerbil is a chronically lowered EP (Schmiedt et al. 2002).

\section{CONCLUSIONS}

1. Young-adult gerbil ears chronically exposed to furosemide were largely normal with regard to morphology except in the extreme basal turn (hook region) where the furosemide was applied via the round window.

2. Reduced immunoreactivity for NKCC in the stria vascularis and spiral ligament was seen mainly in the hook region.

3. Young-adult gerbil ears can adapt to a chronicfurosemide insult over time as seen by both a recovery in physiological measurements and a return to a near-normal morphology in the lateral wall.

4. The chronic-furosemide model of presbyacusis results in EP reductions and elevations in CAP thresholds similar to those observed in quiet-aged gerbils, with the best correspondence after 7 days of furosemide exposure.

5. The activity of the low-SR fiber population with $\mathrm{CFs} \geq 6 \mathrm{kHz}$ declined in furosemide-treated gerbils.
The decline was observed in single fibers directly and was further confirmed with recovery function tests of CAP responses after prior stimulation.

6. The results indicate that the decreased activity of low-SR auditory fibers along with the changes in CAP thresholds, I/O functions, and DPOAEs seen in furosemide-treated young gerbils and quiet-aged gerbils are direct consequences of a chronically lowered EP and suggest that a reduction in the EP is a major cause of the functional changes associated with metabolic presbyacusis.

\section{ACKNOWLEDGMENT}

This work was supported by: National Institutes of Health Grants DC07506 (H.L.); DC00422 (H.L. and J.R.D.); DC00713 (B.A.S.); and AG14748 (R.A.S.). This work was conducted in a facility with support from the National Institutes of Health, Grant Number C06 RR015455 from the Extramural Research Facilities Program of the National Center for Research Resources. The authors are grateful to Hiro-oki Okamura, Jennifer Shearer, and James Nicholson for their invaluable comments and technical assistance.

\section{REFERENCES}

Conlee JW, Gerity LC, Bennett ML (1994) Ongoing proliferation of melanocytes in the stria vascularis of adult guinea pigs. Hear Res 79(1-2):115-122

Cooper NP, Rhode WS (1992) Basilar membrane mechanics in the hook region of cat and guinea-pig cochleae: sharp tuning and nonlinearity in the absence of baseline position shifts. Hear Res 63(1-2):163-190

Crouch JJ, Sakaguchi N, Lytle C, Schulte BA (1997) Immunohistochemical localization of the $\mathrm{Na}-\mathrm{K}-\mathrm{Cl}$ co-transporter (NKCC1) in the gerbil inner ear. J Histochem Cytochem 45(6):773-778

Davis H (1958) A mechano-electric theory of cochlear action. Ann Otol Rhinol Laryngol 67:789-801

Davis H (1965) A model for transducer action in the cochlea. Cold Spring Harb Symp Quant Biol 30:180-190

Frisina RD, Karcich KJ, Tracy TC, Sullivan DM, Walton JP, Colombo J (1996) Preservation of amplitude modulation coding in the presence of background noise by chinchilla auditory-nerve fibers. J Acoust Soc Am 99(1):475-490

Gratton MA, Schmiedt RA, Schulte BA (1996) Age-related decreases in endocochlear potential are associated with vascular abnormalities in the stria vascularis. Hear Res 94:116-124

Gratton MA, Smythe BJ, Lam CF, Boettcher FA, Schmiedt RA (1997) Decline in the endocochlear potential corresponds to decreased $\mathrm{Na}, \mathrm{K}-\mathrm{ATP}$ ase activity in the lateral wall of quiet-aged gerbils. Hear Res 108:9-16

Hellstrom LI, Schmiedt RA (1990) Compound action potential input/output functions in young and quiet-aged gerbils. Hear Res 50:163-174

Hequembourg S, Liberman MC (2001) Spiral ligament pathology: a major aspect of age-related cochlear degeneration in $\mathrm{C} 57 \mathrm{BL} / 6$ mice. J Assoc Res Otolaryngol 2(2):118-129

Hirose K, Liberman MC (2003) Lateral wall histopathology and endocochlear potential in the noise-damaged mouse cochlea. J Assoc Res Otolaryngol 4(3):339-352 
Honrubia V, Ward PH (1969) Dependence of cochlear microphonics and the summating potential on the endocochlear potential. J Acoust Soc Am 46:388-392

Jayakumar AR, Liu M, Moriyama M, Ramakrishnan R, Forbush B 3rd, Reddy PV, Norenberg MD (2008) Na-K-Cl Cotransporter-1 in the mechanism of ammonia-induced astrocyte swelling. J Biol Chem 283:33874-33882

Keithley EM, Ryan AF, Woolf NK (1989) Spiral ganglion cell density in young and old gerbils. Hear Res 38:125-134

Kiang NYS, Watanabe T, Thomas EC, Clark LF (1965) Discharge patterns of single fibers in the cat's auditory nerve. MIT, Cambridge

Kiang NYS, Moxon EC, Levine RA. Auditory-nerve activity in cats with normal and abnormal cochleas. In Wolstenholme GEW, and Knight J. J\&A Churchill, London 1970

Kiang NYS, Liberman MC, Levine RA (1976) Auditory-nerve activity in cat exposed to ototoxic drugs and high-intensity sound. Ann Otol 85:752-767

Lang H, Schulte BA, Schmiedt RA (2002) Endocochlear potential and compound action potential recovery functions in the C57BL/6J mouse. Hear Res 172:118-126

Lang H, Schulte BA, Schmiedt RA (2003) Effects of chronic furosemide treatment and age on cell division in the adult gerbil inner ear. J Assoc Res Otolaryngol 4(2):164-175

Lang H, Schulte BA, Goddard JC, Hedrick M, Schulte JB, Wei L, Schmiedt RA (2008) Transplantation of mouse embryonic stem cells into the cochlea of an auditory-neuropathy animal model: effects of timing after injury. J Assoc Res Otolaryngol 9(2):225-240

Liberman MC (1978) Auditory-nerve response from cats raised in a low-noise chamber. J Acoust Soc Am 63(2):442-455

Liberman MC, Oliver ME (1978) Morphometry of intracellularlylabeled neurons of the auditory nerve: correlations with functional properties. J Comp Neurol 223:163-176

Mills JH, Schmiedt RA, Kulish LF (1990) Age-related changes in auditory potentials of Mongolian gerbil. Hear Res 46:201-210

Mills JH, Schmiedt RA, Schulte BA, Dubno JR (2006) Age-related hearing loss: a loss of voltage, not hair cells. Semin Hear 27:228236

Mroz EA, Sewell WF (1989) Pharmacological alterations of the activity of afferent fibers innervating hair cells. Hear Res 38(12):141-162

Müller M (1996) The cochlear place-frequency map of adult and developing Mongolian gerbil. Hear Res 94:148-156

Murnane OD, Prieve BA, Relkin EM (1998) Recovery of the human compound action potential following prior stimulation. Hear Res 124:182-189

Ohlemiller KK (2004) Age-related hearing loss: the status of Schuknecht's typology. Curr Opin Otolaryngol Head Neck Surg 12(5):439-443

Ohlemiller KK, Echteler SM (1990) Functional correlates of characteristic frequency in single cochlear nerve of the Mongolian gerbil. J Comp Physiol A Sens Neural Behav Physiol 167:329-338

Ohlemiller KK, Siegel JH (1994) Cochlear basal and apical differences reflected in the effects of cooling on responses of single auditory nerve fibers. Hear Res 80:174-190

Ohlemiller KK, Echteler SM, Siegel JH (1991) Factors that influence rate-versus-intensity relations in single cochlear nerve fibers of the gerbil. J Acoust Soc Am 90:274-287

Rarey KE, Yao X (1996) Localization of $\mathrm{Cu} / \mathrm{Zn}-\mathrm{SOD}$ and Mn-SOD in the rat cochlea. Acta Otolaryngol 116(6):833-835

Relkin EM, Pelli DG (1987) Probe tone thresholds in the auditory nerve measured by two-interval forced-choice procedures. J Acoust Soc Am 82(5):1679-1691

Relkin EM, Doucet JR, Stearns A (1995) Recovery of the compound action potential following prior stimulation: evidence for a slow component that reflects recovery of low spontaneous-rate auditory neurons. Hear Res 83:183-189
Roberson DW, Rubel EW (1994) Cell division in the gerbil cochlea after acoustic trauma. Am J Otol 15(1):28-34

Ruggero MA, Rich NC (1991) Furosemide alters organ of Corti mechanics: evidence for feedback of outer hair cells upon the basilar memebrane. J Neurosci 11:1057-1067

Russell IJ (1983) Origin of the receptor potential in inner hair cells of mammalian cochlea-evidence for Davis theory. Nature 301:334-336

Rybak LP (1993) Ototoxicity of loop diuretics. Otolaryngol Clin North Am 26:829-844

Sakaguchi N, Crouch JJ, Lytle C, Schulte BA (1998) Na-K-Cl cotransporter expression in the developing and senescent gerbil cochlea. Hear Res 118(1-2):114-122

Salt AN (2005) Pharmacokinetics of drug entry into cochlear fluids. Volta Rev 105(3):277-298

Salt AN, Ma Y (2001) Quantification of solute entry into cochlear perilymph through the round window membrane. Hear Res 154:88-97

Salvi R, Perry J, Hamernik RP, Henderson D (1982) Relationships between cochlear pathologies and auditory nerve and behavioral responses following acoustic trauma. In: Hamernik R, Henderson D, Salvi RJ (eds) New perspectives in noise-induced hearing loss. Raven, New York, pp 165-188

Schmiedt RA (1989) Spontaneous rates, thresholds and tuning of auditory-nerve fibers in the gerbil: comparisons to cat data. Hear Res 42:23-35

Schmiedt RA (1996) Effects of aging on potassium homeostasis and the endocochlear potential in the gerbil cochlea. Hear Res 102:125-132

Schmiedt RA. The physiology of cochlear presbyacusis. The aging auditory system: perceptual characterization and neural bases of presbyacusis. In: Gordon-Salant S, Frisina RD, Poper AN, Fay RR (eds). Springer handbook of auditory research, Springer Verlag, Heidelberg. Ch.2. 2009

Schmiedt RA, Mills JH, Adams JC (1990) Tuning and suppression in auditory nerve fibers of aged gerbils raised in quiet or noise. Hear Res 45:221-236

Schmiedt RA, Mills JH, Boettcher FA (1996) Age-related loss of activity of auditory-nerve fibers. J Neurophysiol 76:2799-2803

Schmiedt RA, Spicer SS, Schulte BA (1999) Morphologic and physiologic changes in gerbil cochleas exposed to chronic infiltration of furosemide into perilymph. Assoc Res Otolaryngol Abstr 22:134

Schmiedt RA, Lang H, Okamura H (2000) Model of metabolic presbyacusis: neural response under condition of chronically-low endocochlear potentials induced with furosemide. Assoc Res Otolaryngol Abstr 23:282

Schmiedt RA, Lang H, Okamura HO, Schulte BA (2002) Effects of furosemide applied chronically to the round window: a model of metabolic presbyacusis. J Neurosci 22(21):9643-9650

Schuknecht HF (1974) "Presbyacusis" in pathology of the ear. Harvard University Press, Cambridge

Schuknecht HF, Gacek MR (1993) Cochlear pathology in presbyacusis. Ann Otol Rhinol Laryngol 102(1 Pt 2):1-16

Schulte BA, Schmiedt RA (1992) Lateral wall Na,K-ATPase and endocochlear potentials decline with age in quiet-reared gerbils. Hear Res 61:35-46

Sewell WF (1984) The relation between the endocochlear potential and spontaneous activity in auditory nerve fibers of the cat. J Physiol Lond 347:685-696

Slepecky NB, Galsky MD, Swartzentruber-Martin H, Savage J (2000) Study of afferent nerve terminals and fibers in the gerbil cochlea: distribution by size. Hear Res 144:124-134

Spicer SS, Schulte BA (2002) Spiral ligament pathology in quietaged gerbils. Hear Res 172(1-2):172-185

Spicer SS, Gratton MA, Schulte BA (1997) Expression patterns of ion transport enzymes in spiral ligament fibrocytes change in 
relation to strial atrophy in the aged gerbil cochlea. Hear Res 111(1-2):93-102

Suryadevara AC, Schulte BA, Schmiedt RA, Slepecky NB (2001) Auditory nerve fibers in young and quiet-aged gerbils: morphometric correlations with endocochlear potential. Hear Res $161: 45-53$

Taberner AM, Liberman MC (2005) Response properties of single auditory nerve fibers in the mouse. J Neurophysiol 93(1):557569

Tarnowski BI, Schmiedt RA, Hellstrom LI, Lee FS, Adams JC (1991) Age-related changes in cochleas of Mongolian gerbils. Hear Res 54(1):123-134

Wagner N, Cayé-Thomasen P, Laurell G, Bagger-Sjöbäck D, Thomsen $\mathrm{J}$ (2005) Cochlear hair cell loss in single-dose versus continuous round window administration of gentamicin. Acta Otolaryngol 125(4):340-345

Wangemann P, Liu J, Marcus D (1995) Ion transport mechanisms responsible for $\mathrm{K}+$ secretion and the transepithelial voltage across marginal cells of stria vascularis in vitro. Hear Res 84:19-29

Winter IM, Robertson D, Yates GK (1990) Diversity of rate-level functions in the guinea pig auditory nerve. Hear Res 45:191202

Wu T, Marcus DC (2003) Age-related changes in cochlear endolymphatic potassium and potential in CD-1 and CBA/CaJ mice. J Assoc Res Otolaryngol 4(3):353-362

Yamashita H, Shimogori H, Sugahara K, Takahashi M (1999) Cell proliferation in spiral ligament of mouse cochlea damaged by dihydrostreptomycin sulfate. Acta Otolaryngol 119(3):322-325 